\title{
2 \\ Cancer and the Gendered Body
}

On 3 December 1700, noblewoman Sarah Cowper wrote in her diary: 'My breast is unquiet and gives me troublesome apprehensions. I sometimes seem weary of living, yet find myself often in fear of a painfull lingering death'. ${ }^{1}$ Beside the entry was a marginal note in the same hand: 'Fearing a Cancer'. In this chapter, I will argue that Cowper's identification of her breast as the 'troublesome' site where a cancer might breed was, in part, born of contemporary medical and cultural orthodoxy. The feminine body - in particular, the female breast - was, for early modern medical practitioners and lay observers, the paradigmatic site of cancerous growth. This paradigm was rooted in medical, social and aesthetic discourses in which the female body variously appeared as fecund, feeble, dangerous and secret. Moreover, as they attempted to explain cancer's bias toward the supposedly weaker sex, medical practitioners reluctantly engaged with troubling aspects of early modern women's lifecycles, making cancer a disease with the potential to cast light on hidden aspects of the sufferer's conjugal and domestic situation. Women's cancers thus sprang from, and in turn re-inscribed, a model of sexual dimorphism in which the female body appeared physiologically, functionally and pathologically unique.

In exploring the gendering of cancerous disease, this chapter looks in particular to the one-sex/two-sex debate; a discussion which has occupied many scholars since Thomas Laqueur's and Londa Schiebinger's influential proposition of the former model in Making Sex: The Body and Gender from the Greeks to Freud and 'Skeletons in the Closet' respectively. ${ }^{2}$ In brief, the now well-known 'one-sex' model argues that the notion of two sexes distinguished not only by visible genitalia but by internal pathology was virtually unknown prior to the eighteenth century. Until that point, Schiebinger and Laqueur argue, it was usual to think of woman as 
an unfinished or imperfect version of man, with her lesser bodily heat causing her to retain inside her body the generative organs which men had on the outside. Thus the ovaries could be seen as equivalent to the testes, and the cervix to the penis. Only in the eighteenth century did other differences - notably, skeletal differences - emerge. This model is largely based on observations of the similitude of male and female genitalia in anatomical texts, and of the popular idea that the ovaries might produce 'seed' similar to that of the testes. From hence, Laqueur in particular posits women's changing social and economic roles as having influenced suppositions about their internal pathology.

Although the 'one-sex' model has proven valuable, several scholars, most notably Michael Stolberg, have persuasively argued that the location of a dimorphic sexual model as emerging in the late seventeenth or eighteenth century is misjudged, and that sexual dimorphism was in fact prominent in texts dating from the sixteenth century onward. ${ }^{3}$ As Stolberg points out, 'This is not just a question of getting the dates right: if this is true the contexts from which this earlier discourse of sexual difference emerged also differed from that described by Laqueur and Schiebinger' ${ }^{4}$ His own estimation of possible factors in the development of a 'two-sex' model includes an intellectual shift toward empirical observation as well as commercial gains to be had from medical practitioners' specializing in 'women's problems'. ${ }^{5}$ Stolberg's contention is based on a range of evidence, including early modern anatomical drawings and treatises, and writing on sex-specific diseases. In this chapter, I argue that cancer - particularly breast and womb cancers - constituted one such 'sex-specific' disease, which was understood as contingent upon a humoral and anatomical pathology unique to the female sex. It is to be noted, however, that my argument for cancers as linked to sexspecific traits does not preclude a degree of continuity between male and female states. As Gail Kern Paster notes in her 'The Unbearable Coldness of Female Being: Women's Imperfection and the Humoral Economy', the idea that both male and female temperaments could be located on a continuous spectrum, from hot and dry to cold and wet, remained in place even after the notion of genital homology declined. ${ }^{6}$ Notably, however, men occupied most of this range. Women, argues Paster, were confined en masse to the 'cold and wet' end of the humoral spectrum, with any deviance therefrom taken as abnormal or pathological.

Building upon the theme of 'gendered' illness as confirming sexual dimorphism, this chapter views certain aspects of women's lifestyles as implicated in their physiological and social otherness, and associated susceptibility to cancerous disease. In doing so, I touch upon several 
aspects of early modern women's physiology and lifestyles for which there are substantial, and growing, critical literatures beyond the scope of this project to examine extensively. Work on menstruation, maternal nursing and domestic violence is notably heterogeneous, with ongoing debate about, for example, whether menstruation was viewed positively or negatively by medical practitioners, whether the use of wet nurses rose or fell over the seventeenth century and how prevalent spousal abuse was in early modern households. In each of these cases, I have dwelt on the points of consensus between authors rather than their differences: that menstruation was a fraught topic, that medical and religious rhetoric favoured maternal nursing and that domestic violence was often permitted within the law.

The first part of this chapter examines the case for viewing cancer as a 'female' disease, showing that although men might suffer from sexspecific cancers, these were rare and not usually attributed to a male pathology. By contrast, women made up the majority of recorded cancer cases, and their sex-specific cancers were believed to be indexed to their distinctly different biology. This sexed biology is the subject of part two, in which I show how the twinned excremental and generative functions of women's reproductive systems were believed to 'breed' cancers. Finally, I consider some environmental factors primarily affecting women and examine why early modern medical practitioners believed that these factors contributed to the development of cancerous disease. Sex, or lack thereof, maternal breastfeeding or refusal to breastfeed, domestic violence and emotional turmoil were all indicated as 'risk factors', such that a woman's cancer might be read as revealing shameful home truths.

\subsection{A woman's disease?}

In his 'Historical Notes on Breast Cancer', Daniel De Moulin asserts that

[t]he history of carcinoma was for many centuries mainly the history of breast cancer. Only when in the second half of the 19th century anaesthesia and antisepsis had enabled surgery to treat certain internal carcinomas as well, interest in malignancies other than those of the breast sprang into being. ${ }^{7}$

De Moulin's statement makes some questionable assumptions about early modern surgery, as Chapter 6 will demonstrate. Nonetheless, is it 
true that in the early modern period, 'breast cancer was cancer'? ${ }^{8}$ The answer, as this section and this chapter shall demonstrate, is a qualified 'yes'. Breast cancer was certainly the predominant form in most medical accounts, for various cultural, pragmatic and medical reasons. Nonetheless, men did suffer from cancers, as well as being positioned as the 'normal' against which female bodies could be cast as pathological.

It has gone unremarked in the few texts dealing with early modern cancers that, on rare occasions, men were diagnosed as suffering from sex-specific tumours - namely, of the testes ('cods' or 'stones') or penis ('yard'). However, there is some, albeit tentative, evidence for such complaints. A few fleeting mentions of cancers on the yard appear in several medical textbooks around the mid-seventeenth century, usually accompanied by prescriptions for the disease. ${ }^{9}$ In the early eighteenth century, John Marten asserted in more detail that 'Swellings or Tumors on the Stones', caused by 'Blows, Falls, \&c.', could 'terminate into a Cancer' if mishandled. ${ }^{10}$ The signs of such a transformation were that 'upon applications to it, it begins to be attended with pricking Pain, \&c.', and such cases 'consequently ought not, or but very cautiously to be medled with'. ${ }^{11}$ Marten's account relied upon the popular belief, outlined later in this chapter, that bruises could cause cancer. It is notable, however, not for indicating 'male cancers' as a subject area, but rather the opposite; male cancers, even when sex specific, were apparently not viewed as allied to pathological traits peculiar to men, or to gender-specific aspects of their lifestyles. Marten's case appeared in a text dealing primarily with venereal diseases, but it was not implied that cancer should be viewed as just reward for contracting the pox any more than for bruising one's 'cods'. It was simply that this was the circumstance most likely to produce a swelling that could be ill-handled. Moreover, there is no evidence that cancer of the penis or testes was treated, as one might expect under a 'one-sex' model, as equivalent to cancer of the womb. ${ }^{12}$ Cures for male cancers appeared either in texts specific to diseases of the reproductive system, or in those dealing especially with cancer, but were seemingly too uncommon to merit mention in the pages of texts on general surgery and physic, where remedies for dermal or breast tumours could be found in abundance.

Overall, only a handful of male-specific cancers were mentioned in early modern medical texts; quite possibly because when it appeared on the genitals, this disease was easily confused with venereal pox, which similarly produced pain, swellings and ulcers, but also because, as I shall contend, theories about the disease's causation meant that medical practitioners did not expect to find cancers here. Neither is there any evidence 
that when it appeared in men, cancer was thought of as a feminising malady. Conversely, even this unusual 1703 account of a man suffering from breast cancer construed the illness in gender-neutral terms:

Hildanus ... tells of one Poteer, an ingenious man, who had a Cancerous Tumour about his left Pap the bigness of a Hens Egg, with which he was troubled many years. Some Physician advised that he would try to dissolve the Tumour and discuss it [with emollients] ... but he no sooner had applyed these to it, but a pain and inflamation arose in the part; so that he was forced to lay that aside and come to the use of a cooling Medicine: The pain and inflamation being allay'd, he applies the Emollients again, but pain succeeded as formerly; and when he found by experience, that these Emollients only raised his pains, and inflamed him, he laid them aside, and the Patient lived a long time after in safety and free from pain. ${ }^{13}$

The subject here is rather the inadvisability of using emollient medicines than Poteer's gender, and the patient is approvingly described as 'ingenious'. Another case of male breast cancer can be found in Robert Bayfield's 1655 Enchiridion Medicum. ${ }^{14}$ Once again, the account is brief and the patient is soon cured with mild medicines. It seems that diagnoses of breast cancer in men during this period were vanishingly rare, and were not linked to gender-specific complaints, as was often the case for women. Where female breast cancer was, as I shall detail, frequently connected to amenorrhea, and hence to the connection between womb and breast, the absence of the womb in men meant that no such conclusions could be drawn. Cases of breast, penile or testicular cancer in men were seemingly viewed as no more nor less allied to their broader humoral makeup than tumours which appeared anywhere else on their bodies.

The contrast between this attitude and that seen in discussion of women's cancers could hardly have been more pronounced. In 1670, the anonymous An Account of the Causes of Some Particular Rebellious Distempers declared:

Cancers are known in part by the Places they fix on, which are the Glands, tho' they may breed in almost all parts of the Body; and this Aegineta confirms, who says, a Cancer may happen to sundry Places, as the Lips, Tongue, Cheeks, Womb, and other loose Glandulous Parts; but were [sic] One has a Cancer in any part besides, Twenty have them in their Breasts. ${ }^{15}$ 
That view had been orthodox, as Luke Demaitre attests, in the medieval period, and would remain so into the eighteenth century, in which Kaartinen argues that 'having breasts at all was the greatest risk of contracting cancer'. ${ }^{16}$ In 1721, for example, An Universal Etymological English Dictionary defined 'Cancer' as 'a dangerous Sore, or Ulcer; as in a Womans Breast'. ${ }^{17}$ Although it is impossible to determine with any accuracy how many cancers, and what kind, were diagnosed in England between 1580 and 1720, Edward Shorter has found that in parts of eighteenth-century Europe, recorded deaths from cancer were up to nine times higher among women than among men. ${ }^{18}$ Furthermore, non-medical texts readily adopted the paradigm of cancer as 'of the (female) breast'. For instance, churchman Thomas Adams's 1615 invective against thieves described them as like 'that disease in the brest, call'd the Cancer'. ${ }^{19}$ Similarly, in John Webster's 1612 The White Devil, Flamineo described himself as 'like a wolf [cancer] in a woman's breast' (5.3.54), while Shakespeare's ambiguous 'canker' often played upon parallels between floral and female bodies. ${ }^{20}$

Cancer was thus paradigmatically a 'woman's disease' in the sense that it was much more frequently identified in women, and that, as both consequence and cause of this bias, the breasts represented the archetypal cancer site. This bias did not mean that men could not suffer from cancers, including some that were sex-specific. However, where men's cancers were generally considered the result of bad diet, bad humours or simply bad luck, women's sex-specific cancers were, as I shall describe, attributed to the peculiar pathology of the female body.

\subsection{Breeding a tumour: cancer and female pathology}

That women were more likely than men to suffer from cancerous disease was a commonplace in early modern medical and popular understandings of the malady. Exactly why this should be the case, however, remains to be explored, and I contend that women's susceptibility to cancers was explained in terms of their sex-specific pathology, and in particular, their peculiar anatomy. The uterus, the female breasts and the connection between them provided a fertile environment for cancers to grow, flourish and even mimic that most paradigmatically female of bodily states, pregnancy.

Arguably the driver behind all 'feminine' cancers, as well as a host of other female-specific disorders, was one mysterious and much-discussed organ, the womb. Fundamental to generation, and remaining 'secret' within the body, the womb, as Katherine Park asserts, 'appeared as 
a - arguably the - privileged object of dissection in medical images and texts'. ${ }^{21}$ Matthew Cobb and Monica Green likewise observe that unlocking the secrets of the female reproductive system seemed for early modern anatomists and medical practitioners a sure route to understanding the mysteries of generation more generally. ${ }^{22}$ While they were consistently fascinated by this organ, however, medical texts also reflected cultural ambivalence about the status of the womb, and in particular one of its main functions, menstruation. On one hand, it was widely accepted that, as Stolberg points out, menstruation provided a system by which excess humours, gathered in the womb, could be expelled from the body, thus preventing illness. ${ }^{23}$ Haemorrhoidal bleeding in men was commonly viewed as an imitation of that process, as were periodic nosebleeds. ${ }^{24}$ On the other hand, however, most medical practitioners believed that women only required such a system because of the lack of perfecting heat in their bodies, which was inadequate for the full concoction or perfection of the blood. ${ }^{25}$ In Stolberg's words, '[T]he need for menstruation, not the evacuation itself, was pathological'. ${ }^{26}$

While menstruation might be a healthy process, menstrual blood was sometimes - particularly prior to the seventeenth century - viewed as excremental and noxious, to the point that certain medical writers believed the proximity of a menstruating woman could kill plants, sour milk and cause infants to become sick. ${ }^{27}$ Furthermore, throughout the early modern period, the womb was commonly viewed as an unreliable organ, prone to dysfunctions which threatened not only the woman, but her unborn children, her family and society at large. The terms in which these dysfunctions were presented were often lurid, explicitly depicting the womb as a negative, though necessary, constituent of the feminine body, which was partly independent of the woman in whom it 'resided'. In 1636, for example, John Sadler wrote in The Sick Woman's Private Looking-Glasse - purportedly aimed at a female audience - that 'from the wombe comes convulsions, epilepsies, apoplexies, palseyes, hecticke fevers, dropsies, malignant ulcers, and to be short, there is no disease so ill but may procede from the evill quality of it'. ${ }^{28}$ Still more dramatically, a translated work by the French physician Jean Riolan, printed in 1657 , insisted that

[t] he womb is the Root, Seed plot and foundation of very near al womens Diseases, being either bred in the womb, or occasioned thereby.

If it be troubled with an hot distemper and inflamed, it causes intollerable burnings, the Feaver Synochos and the burning Feaver, very 
troublesome Itchings and finally it brings exulcerations, the Cancer and Gangraena.

If it be stung with fervent Lust, it becomes enraged, causes Uterine fury and Madness; wil not let the Patients rest, but invites them to shake and agitate their Loins, that they may be disburthened of their Seed; and at last, they become shameles and ask men to lie with them.

Somtime it is drawn out of its place towards the sides, and is carryed this way and that way, as far as the Ligaments and Connexions of the Womb wil give leave; and it wil rise directly to the Liver, Stomach and Midrif, that it may be moistened and fanned; it Causes Choaking and Stranglings, and raises terrible and violent motions and Convulsions in the Body.

In a word, the Womb is a furious Live-wight in a Live-wight; punnishing Poor women with many Sorrows. ${ }^{29}$

In this description, the womb acted in ways which made clear that it had no functional counterpart in the male body, threatening the life of the afflicted woman, and disrupting familial and societal structures by inducing inappropriate lust. It was, like cancer, both of and hostile to oneself, 'an Animal in an Animal', imbued with a degree of sentience and, according to some, 'Brutish understanding'. ${ }^{30}$ Accordingly, one common remedy for the 'Mother', or wandering womb, was to tempt the organ back into its proper place by holding foul smells at the nose and sweet ones under one's skirts. Some sources even attested that the womb continued living for some time after a woman's death. ${ }^{31}$

As Riolan noted, the temperamental womb was also susceptible to cancers. Indeed, it was the only internal organ for which diagnoses of cancer were consistently, if not frequently, advanced. As we have seen, cancers of the fundament or intestines appeared only very occasionally in medical texts. Cancers of the womb, however, were described in more detail in a number of writings across the early modern period, in terms which reiterated medical ambivalence toward that organ. The important visual symptoms of cancer, described in Chapter 1, were obviously absent from these diagnoses and replaced by sensational ones, including pain, amenorrhea, difficulty in urinating, feelings of heaviness and tiredness. ${ }^{32}$ Somewhat problematically, such symptoms were common to many renal and gynaecological conditions, not least pregnancy. To clarify the situation, Lazarius Riverius suggested that one might use 'a Womb-perspective Instrument' to locate the problem. ${ }^{33}$ 
Medical practitioners might also manually examine patients in whom they suspected uterine cancers. For example, the physician and surgeon Edmund King wrote in his casebook that examining a 'Mrs Hutchinson', who complained of constipation and pain in her groin and abdomen, he had 'felt in vagina ... noe passage bigger than to admit the end of a little finger or swan quill' ${ }^{34}$ His tentative diagnosis of a tumour in the 'cervix uteri', however, was only confirmed by Hutchinson's death and post-mortem. ${ }^{35}$

Riverius's 'Womb-perspective instrument' never took off, and manual examinations such as King's were rarely conducted (or, perhaps, rarely recorded). In the absence of reliable means of internal examination, the surest sign of an ulcerated cancer in the womb, agreed upon in most medical texts dealing with this subject, was a foul 'sanies', or discharge. Medical practitioners dwelt at length upon this symptom. Robert Bayfield, for instance, talked of a 'carrion-like filth' in the womb, while Pare asserted that the disease 'poures forth filth or matter exceeding stinking \& carion-like, and that in great plenty'. ${ }^{36}$ Others described the womb as issuing 'a blacke graene matter', which was 'cadaverous' ${ }^{37}$ The emphasis on these substances as unclean was more concentrated than anywhere else in discussions of cancer - it was the definitive sign of the disease, rather than an unfortunate side-effect. Descriptions of 'filth' emanating from the womb clearly echoed fears about the potentially harmful properties of menstrual blood. In the positioning of such matter as 'carrion-like' or 'cadaverous', writers also raised the disturbing image of a disease consuming the body from the interior, just like a rosebud eaten from within by a canker. ${ }^{38}$

Given contemporary ideas about the humoral causes of cancer, the womb's supposed susceptibility to this disease, and the language in which its symptoms were described, are unsurprising. The womb provided a sink for what Riverius described as a 'perpetual Commonshore of Excrements': humours which were viewed as, at best, surplus to requirements, and at worst, degraded and feculent. ${ }^{39}$ When not expelled through the menses, these humours could accrue and stagnate in precisely the way believed to breed tumours. As such, restoring menstruation which had stopped unexpectedly was described as a matter of urgency in texts dealing with all kinds of cancer in women. ${ }^{40}$ The reasons for amenorrhea were diverse, and, as described elsewhere in this book, sometimes environmental. One obvious factor, however, was age. Though it was not generally emphasised, medical practitioners could not help but observe that 'Of twenty Women afflicted with Cancers, fifteen will be found to be aged from forty five to fifty Years, when 
Nature usually puts a stop to the menstrual Evacuations' ${ }^{41}$ Diagnoses of cancer in menopausal women inevitably intersected with prevailing medical and cultural discourses which Stolberg argues positioned the menopausal woman as weak and in precarious health by dint of her cooling humours. ${ }^{42}$

Another obvious means by which the menses might be suddenly interrupted was pregnancy. Although there is no evidence of confusion between the two conditions, it is notable that many of the initial symptoms of conception were cruelly mimicked by uterine cancer. Indeed, 'moles', or false pregnancies - identified by some onlookers as the cause of Mary Tudor's false conception in 1554 - were believed to be masses of tissue somewhat akin to tumours, though, crucially, lacking the malignancy characteristic of cancers. ${ }^{43}$ More broadly, it is evident that, following on from the attribution of zoomorphic sentience to cancers, the disease - in the womb, but also elsewhere - could be perceived as a variety of 'monstrous progeny'. Chapter 4 discusses medical practitioners' habit of comparing cancerous tumours at every stage with organic objects with marked potential for growth or generation, such as seeds, nuts and eggs. Cancers were also repeatedly characterised as having been 'bred' from ill humours, and contemporary interest in spontaneous generation, as described in Chapter 3, vivified the long-held belief that tumours might contain 'al kynd of humours, but also sound bodies, and straunge thinges'. ${ }^{44}$ Most strikingly, throbbing pain in a tumour was sometimes characterised as pulsation. ${ }^{45}$ In 1583, for instance, Philip Barrough asserted that ' $[\mathrm{a}]$ bout the place where cancre is lodged, there is felt a certaine beating or pulse, and as it were a pricking: sometime also (as Celsus saith) the tumour is a sleepe, and as it were deade' ${ }^{46}$ In this context, a cancer's 'breaking out' from the body might be viewed as a grotesque delivery which imitated the dangers of childbirth.

In the case of cancer, the ambivalence traditionally present around the womb was thus particularly strong. Both the excremental and generative functions of the womb fitted with perceptions of how cancerous tumours came about, and the womb's quasi-independence from - even hostility toward - the body in which it 'resided' echoed that attributed to cancer. Nonetheless, womb cancers were recorded only rarely compared to tumours in the breast. The reasons for this apparent contradiction inhered in the supposed peculiarities of female biology and the practicalities of diagnosis. As Chapter 1 describes, medical practitioners noted the near impossibility of diagnosing internal cancers. Even the 'sanies' which might accompany uterine cancers were an uncertain sign, and patients may have been reluctant to consult upon (and doctors reluctant 
to record) a symptom which was also characteristic of some varieties of venereal pox. In any case, it was generally accepted that, while they might be palliated, there was no effective cure, pharmaceutical or surgical, for such complaints. For the early modern medical practitioner, however, disorder in the womb did not necessarily mean that a cancer would arise in that organ. Other, more easily diagnosed, spots could bear the brunt of excremental humours, and first among these was the vulnerable and desirable female breast.

According to most early modern medical textbooks, the womb was, by one means or another, connected to the breast, more directly than to any other part of the body. ${ }^{47}$ For many writers, the connection was a simple physical one, outlined in the seminal works of Galen and Hippocrates and confirmed by their own investigations. ${ }^{48}$ In 1657 , for example, Riolan asserted confidently that

There is a great League, and fellow-feeling, between the Dugs, and the Womb, by reason of two Veins, viz. The Vena Mammaria, or Dug-Vein; and the Epigastrica: and also by the Venae Thoracicae, or Breast-Veins, which are Branches of the Vena Cava, which in the bottom of the Belly, affords the Hypogastrick Vein unto the Womb. ${ }^{49}$

Other practitioners supposed a different arrangement of connecting vessels, or a vaguer 'consent' between the two organs, but it was commonly agreed that the two 'communicated' ${ }^{50}$ As the anonymous $A n$ Account observed, '[T] he Breasts of Women are tender... which upon the flowing of the Courses, that tenderness leaves them' ${ }^{51}$ Further evidence could be found in the way that post-partum women did not menstruate, but did lactate. According to many eminent practitioners, blood which was usually surplus, and hence excreted as menses, was used during pregnancy to sustain the foetus, and was afterwards diverted to the breasts to make milk. ${ }^{52}$ Breast milk might thus be viewed as 'nothing but the menstruous bloud made white in the breasts', having been altered by divine design in order to avoid the alarming sight of infants covered in blood. ${ }^{53}$ Under this model, the female breast was functionally unique; rare reports of male lactation merely imitated the same process.

For those writers concerned with cancer, it was apparent that the connection between breast and womb could endanger as well as sustain life. If nutritive blood might travel from womb to breast in order to be concocted into milk, it was also possible that the excremental, possibly harmful humours associated with menstrual blood could make the same passage. An Account further explained that 'The Ancients observ'd, 
that Women were most troubled with Cancers, upon the stopping of their Monthly Visits', because when bad humours were not discharged through the menses, they were most likely to 'discharge themselves' on the breasts. ${ }^{54}$ That conclusion was shared by medical practitioners across the early modern period, though exactly what was transported, and by what mechanism, was a matter for debate: was it melancholy, atra bilis or another kind of 'burnt Blood'? ${ }^{55}$ Some medical practitioners seemingly believed that the connective structures themselves could also become diseased, though this view was uncommon: John Ward, for example, recalled in his diary a conversation with Walter Needham, in which the eminent physician informed him that in one post-mortem examination 'hee hath seen a string ... going from the breast to the uterus. I suppose it was the mammilarie veins full of knotts which were cancrous, and hung much like ropes of onions'. ${ }^{56}$

Furthermore, breasts were not only rendered vulnerable to humoral 'discharge' by dint of their direct connection to the womb. Rather, susceptibility to absorbing excess humours was a characteristic of the breast itself - or more accurately, the female breast, since the flesh thereof was widely accepted to be of a 'Glandulous' quality. According to the 1656 The Compleat Doctoress, 'The Breasts are naturally thin, spongy, or funguous, and loose; for this reason they are apt to entertaine any crude and melancholy humours, flowing to them either from the Matrix, or from any other parts' ${ }^{57}$ The female breasts' lax structure could be evidenced by palpation and anatomical examination. They were, in most cases, and especially in the older women most susceptible to cancers, visibly larger and less muscular than the male equivalent, differences which were not only visually but medically significant. Moreover, discussions of these tissues' laxity often bore a misogynistic taint. Large breasts, it was suggested, provided a particular abundance of 'loose' flesh in which to breed a cancer:

[T]he swelled Breaths of Ancient Virgins and married women, are liable to the same Diseases. For either by reason of a Flux of Humors or of some bruise, they are inflamed and impostumate... Hence comes an incurable Cancer; Because the Dugs are ful of Kernels and spungy, and therefore ordained by Nature to receive superfluous Humors. ${ }^{58}$

The fleshiness which allowed 'superfluous' humours to gather and form tumours was, for this 1657 text, directly indexed to two kinds of women with minimal libidinal capital, old maids and wives. Elsewhere, large breasts were deemed both 'very unsightly', and indicative of lustfulness, 
such that, as Paster contends, "[t]he large breast is the female metonymy not only of age but of shame and thus of a specifically gendered form of social and bodily inferiority'. ${ }^{59}$ As The Compleat Doctoress's observation of the breasts 'entertaining' crude incoming humours suggests, loose and lax breasts were often thought to indicate loose and lax women, since many believed that 'the cause of [the breasts'] greatnesse is often handling of them' or 'stroaking of them' ${ }^{60}$ The popular Compleat Midwife's Practice, meanwhile, linked breast size and its associated dangers to greed, when it advised that women alter their diet to reduce the breasts, since 'the lesser the Breasts be, the less subject they are to be cancered' ${ }^{61}$ Once again, these bodily responses were at least partly sex-specific. Women's inability to resist either gastronomic or sexual temptation could be ascribed to their naturally weak characters, in contrast to the self-mastery supposedly exercised by men. ${ }^{62}$ In addition, it was believed that older women in particular had 'colder', sedentary bodies in which fat was more apt to congeal and less likely to be fully 'concocted' into blood and spirits. In a literal sense, the female body burned fewer calories. ${ }^{63}$

Medical explanations for the prevalence of breast cancer diagnoses over all other types thus engaged with wider cultural ambivalence about female breasts more generally. It is clear that breasts were sites of sexual desire, both for men looking upon them, and according to Riolan, for women too. 'In ripe Virgins fully Marrigable', he asserted, 'the Dugs are firm and solid':

They become more soft and swelling, when they are transported with a burning desire of carnal Embracements: and by how much the higher they swel without pain, and the fuller Orbe that they make, strowing and Kising one another, the greater is their desire after bodily Pleasure, and it may be guessed that they have tasted the Sweetness of Mans-Flesh. ${ }^{64}$

Writing on the significance of these 'orbs', scholars including Angela McShane Jones and Gail Kern Paster have noted the trend for exposed breasts in fashionable dress during parts of the seventeenth century. ${ }^{65}$ Looking to art, fashion and literature, Marilyn Yalom similarly contends that ' $[t]$ he meaning of the breast in Renaissance high culture was unequivocally erotic'. ${ }^{66}$ Exposed breasts could signal fecundity and erotic potential. Furthermore, the nipples of the breasts were occasionally compared to the head of the penis, 'in that by handling or sucking it becomes erect or stiff' ${ }^{67}$ In related discourses, women were occasionally described as 'milking' the penis during sex, whilst breast milk was itself a remedy for 
male impotence. ${ }^{68}$ Viewing the breasts in these terms did not preclude writers or artists from also valorising their maternal function, and noblewomen were sometimes painted bare-breasted, surrounded by their children. ${ }^{69}$ However, such positive representations of the breasts were strictly conditional; as Margaret R. Miles observes, breasts were commonly represented as either 'extremely perfect' or 'extremely bad'. ${ }^{70}$ To be extremely perfect, the breasts, and the individual to whom they belonged, needed to fulfil a raft of criteria. The breasts should be small, high and youthful, promising the fertility of the bearer; furthermore, she should be modest, chaste and of aristocratic pedigree, as well as (preferably) available for marriage. Breasts which became cancerous might have, by dint of their size and age, failed the demands of perfection even prior to illness. When they became diseased, they offered a sign of illness and decay which was in stark contrast to the erotic and maternal ideals of youth, fecundity and plenitude.

The status of the female body, and more specifically, the female breast, as a paradigmatic site of cancers in this period thus depended on discourses in which ambivalence and mistrust toward sex-specific organs was long established. On one hand, the womb and the breast both possessed the mysterious power to nurture and sustain life. On the other, medical practitioners widely accepted that such generative power was bound up with women's constitutional inability to perfect the matter of their humours, and therefore the contingency of their health on menstruation. As women approached older age, this paradox became increasingly fraught, and the womb appeared, like cancer, as both of and hostile to the body, moving around uncontrollably, and creating monstrous growth. That these concerns were transposed onto the breast reflects both contemporary beliefs about the porosity of that organ, and the pragmatic limitations of early modern diagnosis. The womb was impossible to view in a living patient and produced unreliable symptoms. The breast, however, provided a visible, palpable site from which the destructive and constructive potential of the uterus could be read.

\subsection{Domestic bodies: cancer and female lifestyles}

Women were viewed as uniquely vulnerable to cancer, and in particular to breast cancer, for a number of biological reasons. Yet, early modern practitioners noted the obvious: not all women, menopausal or otherwise, suffered from the disease. As detailed elsewhere in this book, several non-gendered factors were believed to influence one's susceptibility to cancer, how fast it progressed and if it might be cured. However, many 
of the elements medical practitioners identified as rendering one at risk of the disease were, implicitly or explicitly, those which linked the peculiar physiology of women to social or domestic phenomena which were either sex-specific, or affected women to a greater extent than men. This section looks at several of the most prominent: maternal nursing, sex, domestic violence and emotional trauma.

Demonstrating the indivisibility of social and biological bodily functions in the early modern period, the most widely discussed 'risk factor' in texts about cancer, as well as discussions of that disease in household receipt books, midwifery texts and manuals of physic, was the thorny issue of maternal breastfeeding. Lactation, as described earlier, was often thought to involve the flowing of humours into the breasts for concoction into milk; a process which, in contrast to the noxious 'discharge' of excremental humours into that tissue, was essentially healthy. As was often the case in discussions of cancer's cause, however, medical practitioners feared that this healthy process might, for a number of reasons, turn unhealthy. Prone to inflammatory infections such as mastitis, the lactating breast was viewed as a potentially vulnerable organ. In particular, medical practitioners knew that problems arose when, for whatever reason, milk stayed in the breasts and stagnated there. For an early modern audience consistently exposed to religious, cultural and medical debate about the advisability of maternal nursing, that fact was particularly important. As Valerie Fildes and David Harley have documented, the seventeenth and eighteenth centuries saw a steady rise in the number of medical practitioners touting maternal nursing as preferable to wet-nursing, though not necessarily a corresponding shift in behaviour. ${ }^{71}$ The 'failure' of upper-class women to nurse their own infants was, argues Harley, increasingly cast as an issue of public moral and physical health, and, then as now, women who 'refused' to breastfeed were often cast in lurid terms. One 1612 work on childbirth, for example, asserted that there was 'no difference betweene a woman that refuses to nurse her owne childe; and one that kills her child, as soone as she hath conceived'..$^{72}$

The increased risk of breast cancer attendant upon failing to breastfeed one's children was explicitly stated in several medical advice books, from across the early modern period, which held that milk became dangerous when it 'curdled' or 'coagulated' in the breasts. ${ }^{73}$ In 1671, midwife Jane Sharp stated that

[i]f there be too much milk in the breasts after the child is born, and the child will not be able to suck it all, the breasts will very frequently 
inflame, or imposthumes breed in them; they swell and grow red, and are painful, being overstretched, where hard tumours grow: too much blood is the cause of it, or the child is too weak, and cannot draw it forth. ${ }^{74}$

These unspecified 'imposthumes' could easily turn cancerous. Notably, however, such texts did not argue for the immorality of the non-nursing mother, nor cast cancer as her 'punishment'. ${ }^{75}$ Rather, they made conspicuous efforts to explain why one might not nurse, or nurse inadequately, and suggested alternative means for drawing milk from the breasts, including suckling by puppies, by another woman or by 'an instrument designed for that purpose'. ${ }^{76}$ Medical practitioners' apparent disinterest in blaming a non-nursing mother for her cancer was born of several factors. There was, as shall be seen later in this chapter and in the book, a general disinclination to assign blame for cancers. People with cancer were acknowledged to be suffering immensely and usually mortally, and attracted much sympathy. They were also, in the eyes of medical professionals, valuable paying customers. In addition, though they commonly agreed that breast cancer and lactation were linked, medical practitioners were often cagey about whether breastfeeding actually diminished or increased the risks of cancer. Shorter's $A$ History of Women's Bodies records that, in 1798, one continental doctor complained that a 'folkloric belief that lactation caused breast cancer' was responsible for women's refusal to breastfeed. ${ }^{77}$ That 'folklore' may well have been contemporary wisdom in the seventeenth century, when one anonymous household receipt book grouped together cancers of the breast with 'nipping biting in the breasts by giving Children suck'. ${ }^{78}$ Several more medical writers acknowledged a connection between lactation and breast cancer, but were vague as to whether the risk was exacerbated by breastfeeding. ${ }^{79}$ The early modern woman thus faced something of a double bind in relation to this 'risk' factor. Lactation, it was acknowledged, increased personal susceptibility to cancer, but how mothers might sidestep this physiological hazard by altering their behaviour was uncertain, and would remain so for decades to come.

Where lactation presented a biologically unavoidable risk to new mothers, the social structures which made motherhood more generally a woman's duty were also implicated in cancer's cause, often in contradictory ways. Marriage and childbearing almost always represented the most proper and 'natural' lifestyle for an early modern woman. ${ }^{80}$ Texts on cancer sought neither to diminish nor support this institution, but showed how marriage, spinsterhood and celibacy 
all presented biological hazards. It was repeatedly (though still infrequently) observed during this period that nuns appeared particularly susceptible to breast cancer. Dionis, for instance, observed in 1710 that 'the Disease is very rife in Nunneries' ${ }^{81}$ Meanwhile, Madame de Motteville remembered her mistress, Anne of Austria (Queen Consort of France and later regent for her son, Louis XIV), as having on several occasions visited nuns 'all rotten' with breast cancer, recording on one occasion in 1647 that ' $[\mathrm{t}$ ] he disease had so eaten away into the part on which it had fastened that we could see into [the nun's] body' ${ }^{82}$ This link between nuns and cancer seems to have prevailed for much of the early modern period, and across national borders. ${ }^{83}$ Investigating incidences of breast cancer in Italian and Spanish nunneries, Sarah E. Owens cites the Paduan medical practitioner Barnardino Ramazzini, who attested in 1713 that 'tumors of this sort are found in nuns more often than in any other women... Every city in Italy has several religious communities of nuns, and you seldom can find a convent that does not harbor this accursed pest within its walls' ${ }^{84}$ Cancer was in these instances understood as resulting from a combination of sexspecific physiological and circumstantial factors. Simply put, lack of sex meant that a woman had no opportunity to put her 'seed' to use in the creation or nourishing of a child. To expel the seed (concocted blood), nuns therefore needed to menstruate more, and if they did not, they would likely suffer with one of the many diseases caused by excess humours either collecting in and blocking up a part of the body, such as the circulatory vessels of the breast, or stagnating and putrefying in the womb, from whence noxious vapours could affect the stomach and brain. ${ }^{85}$

Celibacy, enforced or elective, thus presented a serious risk to women's health. However, writings on cancer also made clear that married life - the only acceptable sphere for female sexual activity held its own dangers. Throughout sixteenth-, seventeenth- and eighteenth-century medical texts, the tendency of cancer to follow a bruise or fall was prominent. ${ }^{86}$ Multiple medical textbooks suggested that 'blows, strokes, punches', 'falls or bruises', 'a Blow, or some Bruise' or 'a fall, a stripe, a blow, a bruise' were among the most likely causes of cancer, particularly breast cancer. ${ }^{87}$ The physiological basis for this statement was clear. Anyone looking upon a bruise could see the discoloured blood welling under the skin, and conclude that the blue, green or yellow tinge thereof represented a stagnation of melancholy and choleric humours in the part, precisely the substances believed to provoke cancers. The perceived causal link between bruises and 
cancer was so well established that in 1729 , a man was brought to court, though acquitted, for causing cancer by punching a woman in the breast on the street. ${ }^{88}$ Most strikingly, in 1670, An Account gave numerous examples of cancer patients whose tumours appeared after a violent experience:

we have instances without number, of Women that have had them [cancerous tumours] by Blows, Bruises, \&c. as before we have made mention of; and as was the case of a Gentlewoman, whose Husband after a Drunken Bout was thrown into a Fever, and being delirious, upon her giving him something to drink, he hit her Left Breast with his Hand, which caus'd it to Cancerate, of which she soon after dy'd. ${ }^{89}$

A poor Working-Woman, by a Blow upon her Right Breast with the Key of a Door, which she run against, had a great Pain in it that she could not Rest Night nor Day; the Bruise inflam'd and Swell'd, she ran from one to another for help, till at length she was told it was a Cancer, and must be cut off. ${ }^{90}$

A Gentlewoman by a punch upon her Breast by a Man's rushing by her in the Street, had such a Pain, throbbing, and at length Inflammation and Swelling, that she was told it was a Cancer ${ }^{91}$

Each of these cases was individually plausible and reinforced the connection between bruising and cancer. Notably, they all involved the breast, suggesting that the damage caused by a bruise was exacerbated by that organ's 'natural' tendency to receive and absorb excess humours. Taken as a body, however, the unusual detail supplied in these stories becomes conspicuous. The gentlewoman received a blow because her husband was not only drunk, but delirious and feverish; the working woman was hurt by the key of a door which she ran into. Overall, one feels that, as Porter has observed of grotesque bodies, 'the disclaimer doubles as an attention-seizing strategy'. ${ }^{92}$ These accounts actually make more visible the most likely way in which a woman could sustain 'a fall, a stripe, a blow': domestic violence. ${ }^{93}$

The prevalence of spousal violence during the early modern period has been discussed at length by, among others, Garthine Walker, Elizabeth Foyster and Laura Gowing. ${ }^{94}$ Though they emphasise different aspects of the wide variety of activities one might characterise as abusive, they all make clear that early modern married women had relatively little legal protection from husbands who might mentally 
and physically subjugate them, including as a mode of 'reasonable correction'. Women had no right to a separation unless the violence inflicted upon them was deemed life-threatening, and thus might find themselves in situations which imperilled their physical and mental health without legal, economic or practical means of escape. ${ }^{95}$ Not all domestic violence was spousal, and women were also known to enact violence upon servants, children and spouses. Nonetheless, male-on-female violence appears to have been more common, and seems implicit to An Account's convoluted tales of how three women found themselves receiving blows to the chest which had nothing whatsoever to do with the dispositions of their husbands, fathers or masters. Medical practitioners' reluctance to identify domestic violence specifically as a cancer cause is understandable, since to do so would cast aspersions on the situations of those whom they treated for the disease, not to mention their spouses. ${ }^{96}$ Writing in her diary, however, the formidable gentlewoman Sarah Cowper experienced no such compunction. On 23 February 1700, she wrote, with characteristic candour, that '[a] visitor told me it was said the Lady Ang. was like to dy of an Ulcer in her Womb and a Cancer in her Breast both caused by the Barbarous Cruelty of her L[ord] ... with the utmost detestation [I] cou'd see scourged this cruel, brutish L[ord]'. ${ }^{97}$

Cowper's assessment of 'Lady Ang.'s ill health, clearly passed on by a gossiping acquaintance, shows the popular currency of the 'bruise' theory of cancer causation. It also shows how, outside medical textbooks, the physical effects of violence could not be separated from its emotional and social ramifications. Medical practitioners identified grief, anger, brooding and mourning as possibly contributing to the development of cancers in both sexes. ${ }^{98}$ Women, however, were once again at particular risk from a combination of physiology and personal circumstances. Even in normal, peaceful settings, women were thought to be constitutionally less able to moderate their emotions. Evelyne BerriotSalvadore summarises: 'According to a tradition stemming from Aristotle and others, woman was weak, quick to anger, jealous, and false, whereas man was courageous, judicious, deliberate, and efficient' ${ }^{99}$ Being on the receiving end of domestic abuse (emotional or physical) thus necessarily had a particularly strong and uncontrollable effect on the female sex. In women's accounts of violent marriages, fear, as one might expect, featured strongly. ${ }^{100}$ One had to be in fear of one's life in order to justify a court separation, and such an extreme of emotion might be expected to have a damaging effect on already fragile female constitutions. A husband did not necessarily have to beat his wife, however, in order 
to bring about grief, anger, sadness and potential physical harm. Only months after recording the 'Barbarous Cruelty' of Lady Ang.'s husband, Cowper wrote:

A lady of my acquaintance had a Cancer broke in her Breast... it was thought the result of a foul disease she got of her Hus[band], who was known to be a Proffligate man. These are sore calamity, but what gives them inexpressible weight is that (perhaps to palliate his own crimes), he accused her of a design (confederate with the Butler, I think it not likely) to poison him. ${ }^{101}$

Her account bespeaks a complete breakdown of the conjugal relationship, a story of betrayal, recrimination and counter-accusation. Transmission of venereal diseases was, as Gowing notes, sometimes cited as a manifestation of 'cruelty' in separation cases, since it caused physical damage. ${ }^{102}$ Moreover, cancer in this case became, while not a 'shameful' disease as such, a means by which the unsavoury and potentially shameful details of one's domestic circumstances could be surmised by others. Sources such as Cowper's diary are rare, but her entries suggest that some onlookers, medical or otherwise, might have heard of a woman's cancer and begun to speculate about her life behind closed doors.

\section{Conclusion}

In Hephizibah Roskelly's 2012 account of her experience of breast cancer, she dwells upon the seeming betrayal of the mind by the body. 'My feminist thinking', recalls Roskelly, 'had to be rethought when I got the word that something toxic - potentially fatal - lived inside me, and had for awhile, long enough that a body that was nurturing the mind...could have mentioned something'. ${ }^{103}$ Though cancer may no longer formally be considered a 'woman's disease', discourses of risk and debates over treatment remain congregated around the female body, and many of the hot topics in these debates - breastfeeding, childbearing, the effect of grief - remain strikingly similar to those I have identified for the early modern period. Moreover, these accounts seem in places to prefigure Roskelly's sense of the female body as having its own agenda, potentially acting against the person 'inside'. In early modern medicine and culture, it was often accepted that women's lives must be blighted by ill health. Because of their unstable humours, their emotional incontinence and their 'destiny' to bear children, women suffered from an array of sex-specific diseases. Textbooks discussing women's health 
issues far outstripped similar texts about men and underlined this sex's status as not only fairer but weaker. The gendering of cancer as a disease to be found primarily in the female breast was largely a product of this discourse, trading on speculation about women's mysterious anatomy and in particular the 'secret' womb. Cancer texts also recognised that women's lifestyles presented several 'risk factors'. Mindful of their market, medical practitioners were reluctant to state in print that domestic turmoil, and choices (or lack thereof) around breastfeeding and sexual activity, might predispose one to cancerous tumours. Free from such concerns, however, Cowper's diary, providing a fascinating and rare glimpse into lay perceptions of cancer, shows that readers might be all too aware of what medical texts really meant when they described the risks of 'grief' or 'blows', and from whence the greatest risk of these arose for women - their marriages, their masters or their parents.

Cancer might also be viewed as representing the 'pathological' nature of women's bodies more fully than other diseases. Cancerous tumours were both a part of the body, generated and sustained by the humours, and a hostile interloper, eating up one's substance. This paradox closely matched that understood to characterise women's peculiar physiology. The bodily phenomena which made women able to bear children - the womb, the 'coldness' of the body and the excess of humours to be voided through menstruation - were the same as those which 'betrayed' them and so frequently made them ill. More broadly, the generative function was a hazardous one in its own right, since childbirth represented the most perilous event of an early modern woman's life. In constructing cancer as a 'gendered' disease, early modern writers thus depicted the illness as both contingent upon, and imitative of, the double bind of women's life-giving but dangerous bodies.

(c) (i) Except where otherwise noted, this work is licensed under a a copy of this license, visit https://creativecommons.org/version4 